\title{
ANALYTIC NETWORK PROCESS MODEL FOR HIGHWAY CORRIDOR PLANNING
}

\author{
Mongkut Piantanakulchai, Ph.D. ${ }^{1}$ \\ Sirindhorn International Institute of Technology \\ Thammasat University, Rangsit Campus \\ Patumthani 12121, Thailand \\ mongkutp@gmail.com
}

Keywords: Analytic Network Process (ANP), highway corridor planning

Summary: The planning of highway alignment is a complex decision making that involves many objectives and stakeholders. Previous studies applied the Analytic Hierarchy Process (AHP) to prioritize the alternatives of highway alignments. Standard AHP model could not accommodate the variety of interactions, dependencies, and feedback. The Analytic Network Process (ANP) is helpful to deal with interdependent relationship within the multi-objectives and multi-stakeholders environment. This paper demonstrates how to empirically prioritize a set of alternatives by using ANP model. The paper first reviews the planning issues related to the highway corridor planning. Then related characteristics were used to structure the ANP model and scores were computed for prioritizing the potential highway alignments. Engineering practitioners may adopt the weighted criteria for alignment selection or apply the ANP method to prioritize their own set of selection criteria.

\section{Introduction}

\subsection{General}

Highway construction is an important decision made by a government. It plays an essential role in a regional economy, and has long-term effects on the community. Selecting the optimal route is a multidisciplinary decision problem. Various objectives to be satisfied may be in conflict with one other by different views of related stakeholders. The problem becomes more complex because the number of alternative routes involved the geological and constructional uncertainties. Cost/Benefit Analysis (CBA) is normally conducted to verify the economic feasibility of possible alternatives. However, the inadequacy of CBA in dealing with intangible factors and strategic concerns is its main weakness (Shang et al. 2004). Moreover, many cost-benefit studies tend to underestimate the importance of the local society where the impact of the project is felt most strongly (Azis, 1990). In practice, the best alternative is chosen by considering multiple criteria such as economic, engineering, environmental, and social impact, etc.

Highway corridor planning problem is defined by the selection of the optimum corridor alignment based on multiple criteria, for example, minimization of construction problems, maximization of the operational functionality of the project, minimization of the environmental impact, and maximization of the results of the economic investment (Kalamaras et al., 2000).

\footnotetext{
${ }^{1}$ Dr. Mongkut Piantanakulchai is currently a full time faculty at the Civil Engineering Program, Sirindhorn International Institute of Technology, Thammasat University, Rangsit Campus, Thailand. His research area involves the application of multicriteria methods to transportation and engineering planning.
} 
Application of multicriteria methods to the highway corridor planning could be found in literatures. For example, Kale et al. (2004) analyzed the land suitability map for expressway corridor from Mumbai and Pune cities in India. Bailey (2003) applied multicriteria method with the Geographic Information System (GIS) to corridor selection for a proposed interstate highway connector in the southeastern U.S. Azis (1990) applied multicriteria method to rationally measuring the intangible and complex impacts of the Trans-Sumatra highway built in the late 1970's. Chowdhury et al. (2002) proposed the optimization approach based on the Surrogate Worth Tradeoff (SWT) method for continuous problems, and multiattribute utility and minimum tolerance method for discrete problems. Four case studies were illustrated based on actual project data. However, the limitation of their work is the inability to factor in the preferences of multiple decision makers. Other related application included the planning of corridor for power transmission line (Bailey et al., 2005).

Several multicriteria methodologies have been proposed and practiced in highway corridor planning. For example, AHP (Azis 1990, Kalamaras et al., 2000; Bailey, 2003; Piantanakulchai, 2005), outranking system (Rogers and Bruen, 2000), surrogate worth tradeoff, multi-attribute utility, and minimum tolerance method (Chowdhury et al., 2002) Many previous studies applied the Analytic Hierarchy Process (AHP) in selecting the best alignment. However, one of the deficiencies of AHP is that it could not include interrelationship and feedback within the elements in the model. This may result in misleading in the decision making, for example, the famous bridge selection problem (Forman and Selly, 2001). Generally, the criterion of strength is set higher than aesthetics in bridge selection. However, when all bridges are satisfied with the strength requirement, the aesthetic criterion becomes more important no matter how stronger another bridge is. This is an example of a situation when the criterion depends on an alternative. The conventional top-down decision model like AHP does not handle this situation directly and may come out with the decision to select the extremely strong but ugly bridge instead of sufficiently strong and beautiful bridge. The Analytic Network Process (ANP) could handle this sort of decision making problem effectively. This study proposes the Analytic Network Process (ANP) model to handle the multicriteria highway corridor selection problem.

\section{Elements of a Standard ANP Model}

The fundamentals of the Analytic Network Process (ANP) could be found in Saaty (1999). In brief, ANP model consists of the control hierarchies, clusters, elements, interrelationship between elements, and interrelationship between clusters.

Control hierarchies consist of the top level criteria that involves in decision making. Control hierarchy provides overriding criteria for comparing each type of interaction in the network. Saaty (1999) proposed four basic control hierarchies, Benefits, Opportunities, Costs, and Risks which are subsequently called BOCR models, for example, Shang et al. (2004). It is not required to include all four control hierarchies if some criteria are irrelevant, for example, hamburger model illustrated by Saaty (1999) and BCR model presented in Poonikom et al. (2004). The determination of relative weights in ANP is based on the pairwise comparison as in the standard AHP, see Saaty (1980). With respect to any criteria pairwise comparisons are performed in two levels, the element level comparison and the cluster level comparison.

Elements are the entities in the system that interact with each other. They could be a unit of decision makers, stakeholders, criteria or sub criteria (if exists), possible outcomes, and alternatives etc. In complex system which contains a great number of elements it would be very time consuming to measure relative importance of each element with every single element in the system. Instead, elements which share similar characteristics are usually grouped into cluster. The determination of relative weights mentioned above is based on pairwise comparison as in the standard AHP. The weights are then put into the supermatrix that represents the interrelationships of elements in the system. The general form of the supermatrix can be described in Fig. 1.

Where $\mathrm{C}_{\mathrm{N}}$ denotes the $\mathrm{N}^{\text {th }}$ cluster, $\mathrm{e}_{\mathrm{Nn}}$ denotes the $\mathrm{n}^{\text {th }}$ element in the $\mathrm{N}^{\text {th }}$ cluster, and $\mathrm{W}_{\mathrm{ij}}$ block matrix consists of the collection of the priority weight vectors (w) of the influence of the elements in the $i^{\text {th }}$ 
cluster with respect to the $\mathrm{j}^{\text {th }}$ cluster. If the $\mathrm{i}^{\text {th }}$ cluster has no influence to the $\mathrm{j}^{\text {th }}$ cluster then $\mathrm{W}_{\mathrm{ij}}=0$. The matrix obtained in this step is called the initial supermatrix.

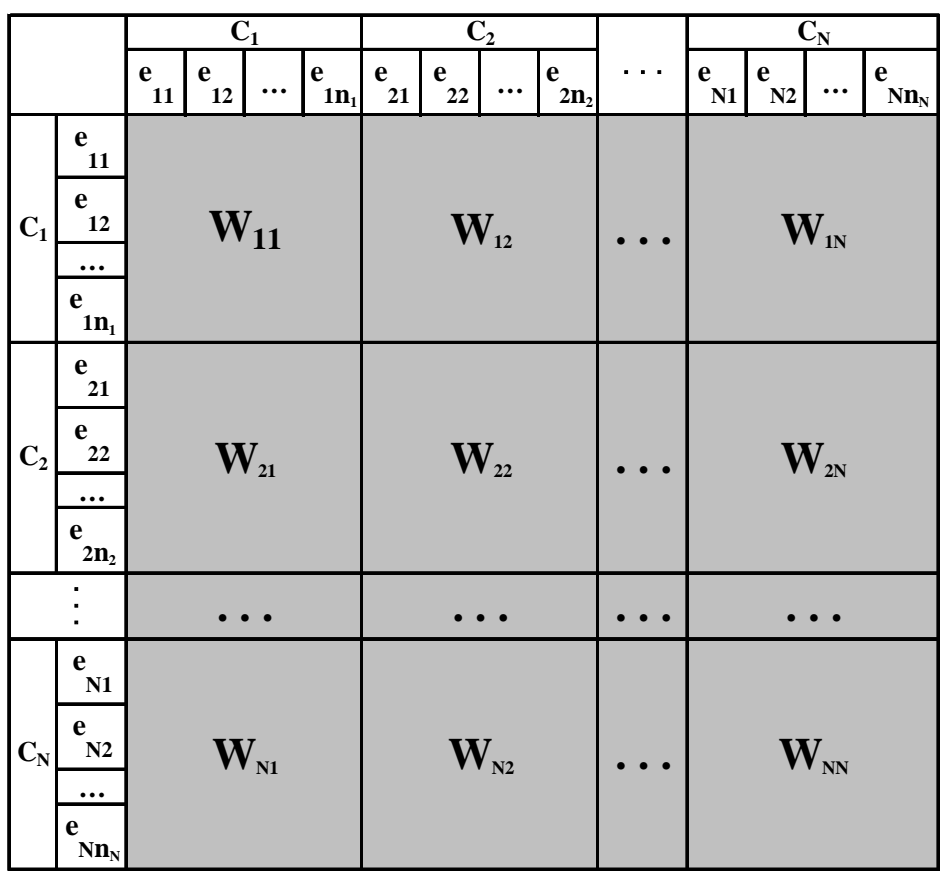

Figure 1. The General Structure of the Supermatrix

As stated earlier, the pairwise comparison is performed in two levels. The eigenvector obtained from cluster level comparison with respect to the control criterion is applied as the cluster weights. This results in a matrix which each of its columns sums to unity. If any block in the supermatrix contains a column that every element is zero, that column of the supermatrix must be normalized after weighting by the cluster's weights to ensure the column sum to be unity. The concept is similar to Markov Chain that the sum of the probabilities of all states equal to one. This matrix is called the stochastic matrix or weighted supermatrix.

The weighted supermatrix is raised to limiting power such as Eq. (1) to get the global priority vectors.

$$
\lim _{k \rightarrow \infty} W^{k}
$$

If the supermatrix has the effect of cyclicity, there may be two or more $\mathrm{N}$ limiting supermatrices. In this case, the Cesaro sum is calculated as in Eq. (2) to get the average priority weights.

$$
\lim _{k \rightarrow \infty}\left(\frac{1}{N}\right) \sum_{i=1}^{N} W_{i}^{k}
$$

\section{ANP Model for Highway Corridor Planning}

The framework for multicriteria evaluation of transport projects by ANP was proposed by Shang et al. (2004). The overall decision problem was disaggregated into four control subnets, benefit, cost, opportunity, and risk. In their study, the decision makers and other stakeholders interact to each other in the network called influence network. With respect to a specific criterion, the preference weight by each alternative is obtained from the limit super matrix of the influence network. On the other side, the weight 
of each sub criterion is obtained by the limit super matrix of the overall decision problem. The preference weight of each alternative is then multiplied with the importance weight of each sub criterion to the total system. Summation of weighted score gives the priority of an alternative. It could be seen that their formulation requires the decision makers to compare the alternatives based criteria at the most upper level criteria (more abstract). Therefore, their model is most useful to compare fairly different projects. In their study, interactions among decision makers and stakeholders were modeled by including all feedbacks within the influence network. While strong emphasis was put on the influence network, however, the interactions among elements in the super matrix of the overall decision problem were less specified. This could be illustrated by many zero elements in their super matrix, for example, the benefit control matrix (see Shang et al. (2004), Table III). It should be noted that how the super matrix is formulated depends on the scale and nature of the decision making problem being considered. For the highway corridor selection problem, the alternatives may not be much different when considered at upper level criteria. This would make the decision more difficult. The judgment would be easier at lower level criteria or at indicator level. In this study, in order to capture the interactions in lower level criteria the super matrix is designed to include the clusters of stakeholders, main objectives, sub objectives, indicators, and alternatives respectively. The decomposition of the decision making problem into lower levels would benefit in two folds. Firstly, the judgment is done easier at the lower level than at the upper level. Secondly, experts in various fields, stakeholders, and decision makers could participate in the decision making process in a well structured environment. For example, experts in each field would make the lower level judgment about the importance of subcriteria in their field while the different stakeholders may be able to put their preference on the criteria differently in the upper level.

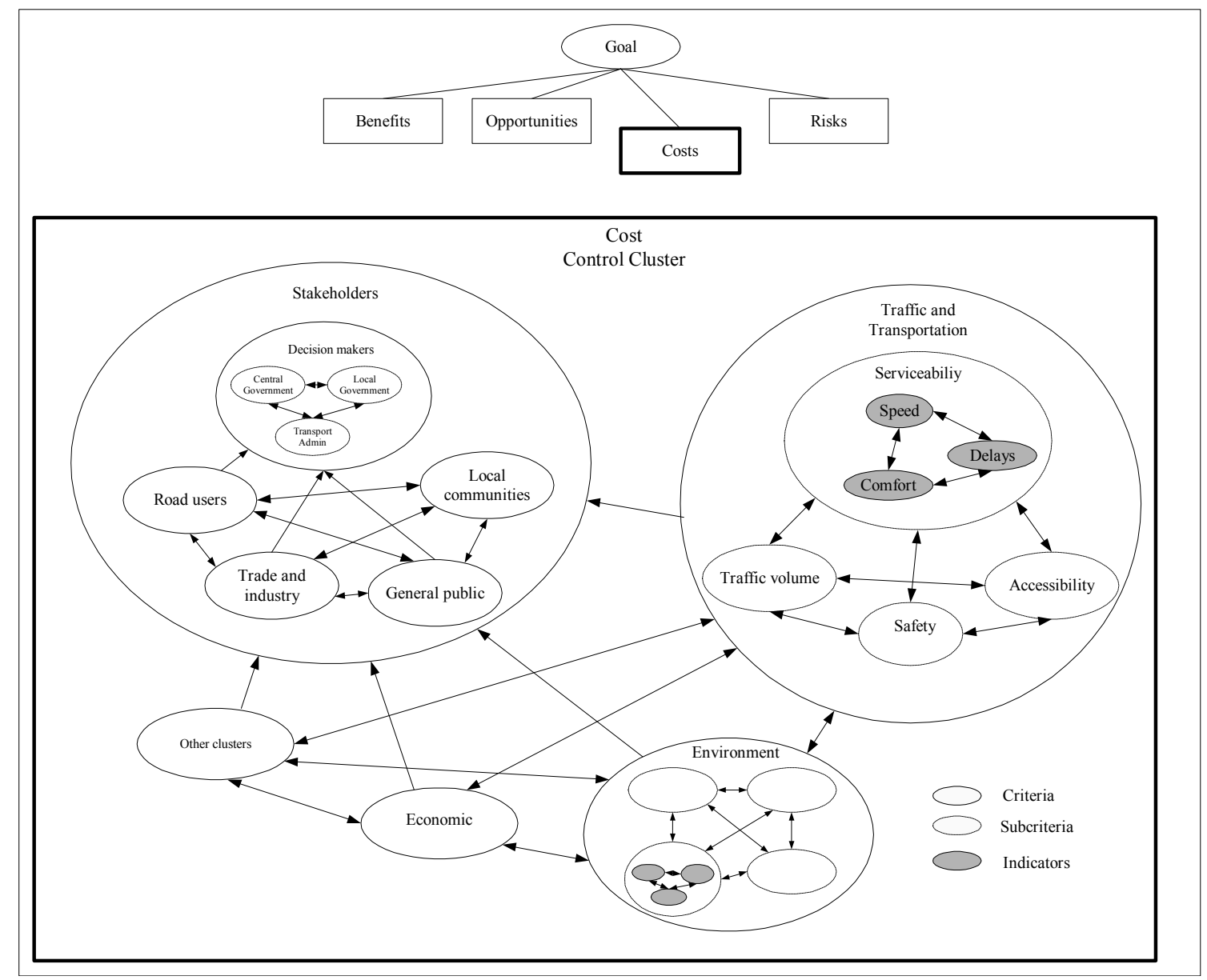

Figure 2. An Example of the Structure of ANP for Highway Corridor Planning

Different corridor has a different impact to the economy and society. The impact is a result of the interaction among various components of the system, for example, engineering, economic, and social 
impacts, etc. In fact, there is no optimum alignment because different stakeholders are interested in different objectives. For instance, the government may be interested in regional economic development while the environmentalists may prefer to preserve the nature. In addition, some objectives are positively related, but others may be negatively related. As a result, based on specific indicator selected, the evaluation of alternatives will be different. Which objective should be considered and the importance of each objective are essential in the analysis. Based on ANP method, experts from different fields should be interviewed to decide the major criteria and sub criteria in their field for evaluating different alignments. The stakeholder level composed of several parties exerting influence into the decision process. These parties could be, for example, the transportation administrators, municipal government, and the local communities. These parties play different roles in viewing the project criteria. For example, the local community may be more interested in the environmental and social effects. The transportation administers may have objectives to increase the mobility of people and goods within the study area while the municipal government may have to consider most of the project criteria. The decision of a stakeholder may be influenced by the decision of other groups. This decision process could be included in the analysis under the framework of ANP by introducing the interdependence or feedback. The objectives of each stakeholder could be decomposed into major criteria categories, for instance, engineering, economic, environmental, and social criteria. It is noted that the stakeholders may have different expectations on these criteria categories. Hence, ANP facilitates integration of their expectation to form the composite objective weights after taking into account their various interest and interactions. Fig. 2 shows an example of ANP framework for highway corridor planning. To exemplify the selected cost control hierarchy is illustrated in detail. The structure of the supermatrix applied in this study is shown in Fig. 3.

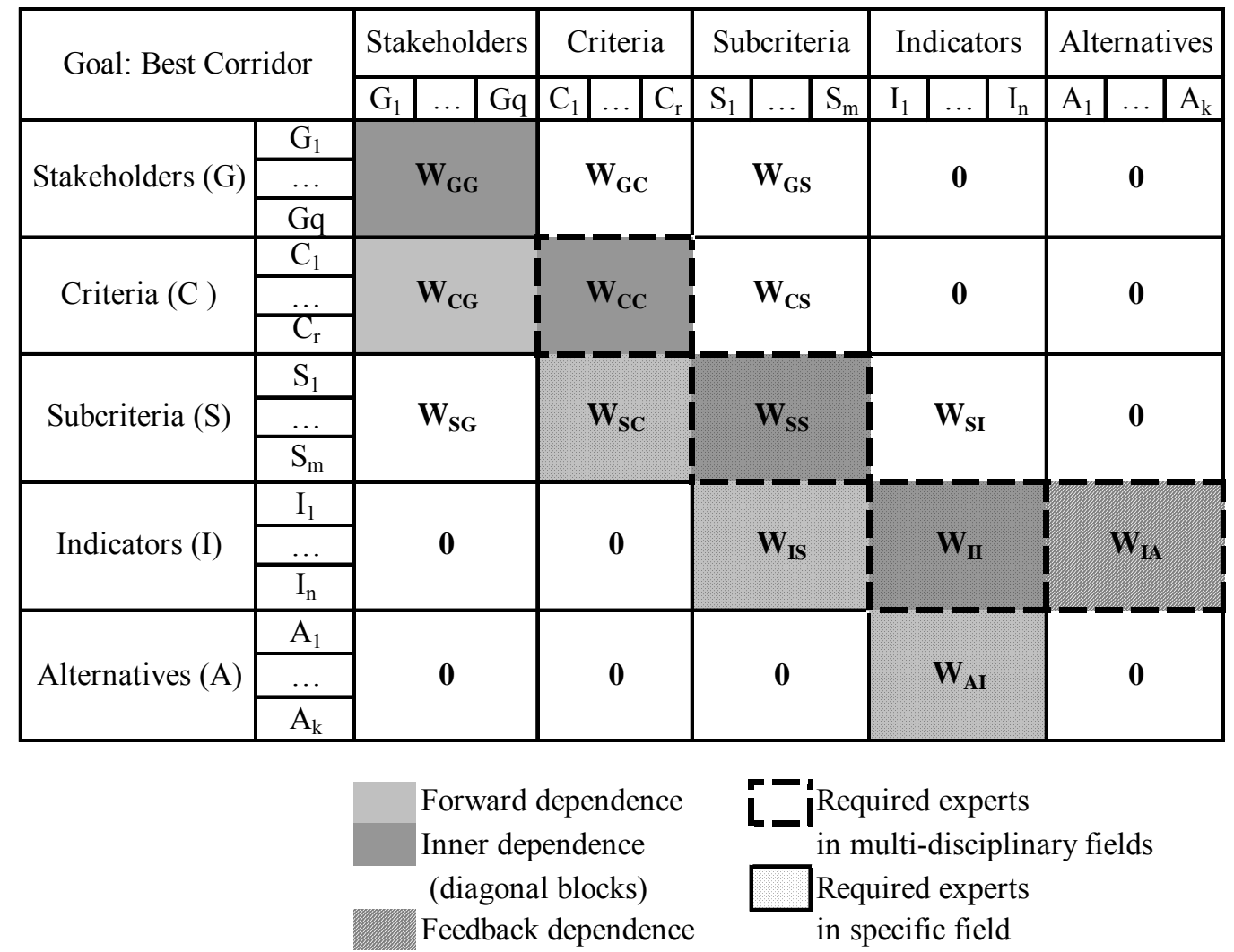

Figure 3. The Basic Structure of the Supermatrix for Highway Corridor Planning

From Fig. 3 it should be noted that all feedback dependences require the expert in multi-disciplinary fields that could judge the relative importance of upper level criteria with respect to a single lower criterion or indicator. For example, each stakeholder may specify their preference of criteria. The decision is therefore based on their own preferences and pressure from other stakeholders (inner 
dependence). Other blocks without shading are possible submatrices that could be included to enhance the model's information, for example, $\mathrm{W}_{\mathrm{SI}}$. The feedback dependence block, $\mathrm{W}_{\mathrm{IA}}$, indicates the relative importance of each indicator based on each alternative. For example, corridors being considered may create significant impact in different impact categories. Therefore, the relative importance of each impact created by different corridor may be different. Table 2 shows typical ANP elements considered in highway corridor planning.

Table 2. Typical ANP Elements Considered In Highway Corridor Planning

\begin{tabular}{|l|l|l|}
\hline 0. Stakeholders & O-A & Government and public administrators \\
\cline { 2 - 3 } & 0-B & Road users \\
\hline & 0-C & Trade and industry \\
\hline & 0-D & Local Community \\
\cline { 2 - 3 } & 0-E & General public \\
\hline
\end{tabular}

\begin{tabular}{|c|c|c|c|}
\hline Criteria & & Subcriteria & Indicators \\
\hline \multirow[t]{6}{*}{ 1. Economic } & & Initial investment & \begin{tabular}{|l|l|}
1 & Investment costs \\
\end{tabular} \\
\hline & $1-\mathrm{B}$ & Operating and maintenance costs & 1 O\&M costs \\
\hline & \multirow{2}{*}{$1-\mathrm{C}$} & \multirow{2}{*}{ Economic returns } & \begin{tabular}{|l|l|l|l}
1 & $B / C$ \\
\end{tabular} \\
\hline & & & \begin{tabular}{|l|l|}
2 & Return period \\
\end{tabular} \\
\hline & 1-D & Tourism development & \begin{tabular}{|l|l|}
1 & Qualitative \\
\end{tabular} \\
\hline & $1-\mathrm{E}$ & Trade and industial development & 1 Qualitative \\
\hline \multirow[t]{7}{*}{ 2. Engineering and construction } & $2-\mathrm{A}$ & Physical suitability of land & 1 Qualitative \\
\hline & \multirow{2}{*}{ 2-B } & \multirow{2}{*}{ Geometric of road } & \begin{tabular}{|l|l} 
& Horizontal curves (No. of curves and curve radius) \\
\end{tabular} \\
\hline & & & \begin{tabular}{|l|l|}
2 & Vertical curves (\% grade changes) \\
\end{tabular} \\
\hline & \multirow{3}{*}{$2-\mathrm{C}$} & \multirow{3}{*}{ Ease or difficulties in construction } & \begin{tabular}{|l|l|}
1 & Tunnel length \\
\end{tabular} \\
\hline & & & \begin{tabular}{|l|l|}
2 & Bridges (No. of bridges and span length) \\
\end{tabular} \\
\hline & & & \begin{tabular}{|l|l|}
3 & Cut\&fill volume \\
\end{tabular} \\
\hline & 2-D & Future expansion and improvement & \begin{tabular}{|l|l|}
1 & Qualitative \\
\end{tabular} \\
\hline \multirow[t]{12}{*}{ 3. Traffic and Transportation } & $3-\mathrm{A}$ & Traffic volume & \begin{tabular}{|l|l|}
2 & Traffic volume \\
\end{tabular} \\
\hline & \multirow{3}{*}{ 3-B } & \multirow{3}{*}{ Serviceability } & \begin{tabular}{|l|l|}
1 & Average speed \\
\end{tabular} \\
\hline & & & \begin{tabular}{|l|l|l}
2 & Average delay \\
\end{tabular} \\
\hline & & & \begin{tabular}{|l|l|}
3 & Comfort (qualitative) \\
\end{tabular} \\
\hline & $3-\mathrm{C}$ & Accessibility & \begin{tabular}{|l|l|}
1 & No. of accessible communities \\
\end{tabular} \\
\hline & \multirow{2}{*}{ 3-D } & \multirow{2}{*}{ Safety } & \begin{tabular}{|l|l}
1 & Horizontal curves (No. of curves and curve radius) \\
\end{tabular} \\
\hline & & & \begin{tabular}{|l|l|}
2 & Vertical curves (\% grade changes) \\
\end{tabular} \\
\hline & \multirow{4}{*}{$3-\mathrm{E}$} & \multirow{4}{*}{ Efficiency of network } & \begin{tabular}{|l|l|}
1 & PCU-km \\
\end{tabular} \\
\hline & & & \begin{tabular}{|l|l|}
2 & PCU-hr \\
\end{tabular} \\
\hline & & & \begin{tabular}{|l|l|}
3 & Average speed \\
\end{tabular} \\
\hline & & & \begin{tabular}{|l|l|l}
4 & $\mathrm{~V} / \mathrm{C}$ \\
\end{tabular} \\
\hline & $3-\mathrm{F}$ & Connection to other modes & \begin{tabular}{|l|l|}
1 & Qualitative \\
\end{tabular} \\
\hline \multirow[t]{16}{*}{ 4. Environment } & $4-\mathrm{A}$ & Change in land topography & \begin{tabular}{|l|l|l|}
1 & Cut\&fill volume \\
\end{tabular} \\
\hline & 4-B & Soil erosion & \begin{tabular}{|l|l|l}
1 & Affected area by soil type \\
\end{tabular} \\
\hline & \multirow{3}{*}{$4-\mathrm{C}$} & \multirow{3}{*}{ Air } & 1 |Number of receptors (communities) \\
\hline & & & \begin{tabular}{|l|l|l}
2 & Number of receptors (schools) \\
\end{tabular} \\
\hline & & & \begin{tabular}{|l|l|}
3 & Number of receptors (temples, mosques) \\
\end{tabular} \\
\hline & \multirow{4}{*}{ 4-D } & \multirow{4}{*}{ Noise } & \begin{tabular}{|l|l|l} 
& Number of receptors (communities) \\
\end{tabular} \\
\hline & & & \begin{tabular}{|l|l|l|l}
2 & Number of receptors (schools) \\
\end{tabular} \\
\hline & & & \begin{tabular}{|l|l|}
3 & Number of receptors (temples, mosques) \\
\end{tabular} \\
\hline & & & \begin{tabular}{|l|l|}
4 & Tunnel's length (during construction only) \\
\end{tabular} \\
\hline & $4-\mathrm{F}$ & Vibration & Same indicators as air and noise impact \\
\hline & \multirow{2}{*}{$4-G$} & \multirow{2}{*}{ Water } & \begin{tabular}{|l|l|}
1 & Tunnel's length (underground water) \\
\end{tabular} \\
\hline & & & \begin{tabular}{|l|l|}
2 & Number of crossed streams and type of structure \\
\end{tabular} \\
\hline & $4-\mathrm{H}$ & Energy & \begin{tabular}{|l|l|}
1 & Energy used/saved \\
\end{tabular} \\
\hline & 4-I & Watershed areas & \begin{tabular}{|l|l|}
1 & Area affected by type of watershed area \\
\end{tabular} \\
\hline & $4-\mathrm{J}$ & Forrest & \begin{tabular}{|l|l|}
1 & Area affected by type of forest \\
\end{tabular} \\
\hline & $4-\mathrm{K}$ & Wildlife & \begin{tabular}{|l|l|l|l|l}
1 & Area affected by type of reserved land for wildife
\end{tabular} \\
\hline 5. Land use & $5-\mathrm{A}$ & Land development or land use change & \begin{tabular}{|l|l|}
1 & Qualitative \\
\end{tabular} \\
\hline & $5-\mathrm{B}$ & Harmony of land use and road usage & 11 Qualitative \\
\hline & $5-\mathrm{C}$ & Consistency with city development plan & 1 Qualitative \\
\hline & $5-\mathrm{D}$ & Sustainability development of city & \begin{tabular}{|l|l|l}
1 & Qualitative \\
\end{tabular} \\
\hline 6. Social & $6-\mathrm{A}$ & Relocation of residences & \begin{tabular}{|l|l|}
1 & No. of relocated residences \\
\end{tabular} \\
\hline & 6-B & Education & \begin{tabular}{|l|l|}
1 & Qualitative \\
\end{tabular} \\
\hline & $6-\mathrm{C}$ & Public health & \begin{tabular}{|l|l|l}
1 & Qualitative \\
\end{tabular} \\
\hline & 6-D & Community acitivities (cultural, religion) & \begin{tabular}{|l|l|l}
1 & Qualitative (related with noise impact) \\
\end{tabular} \\
\hline & $6-\mathrm{E}$ & Aesthetics and visual impact & \begin{tabular}{|l|l|l|l|l}
1 & Qualitative \\
\end{tabular} \\
\hline
\end{tabular}




\section{A Numerical Example: A Case Study of Highway Corridor Planning: in the South of Thailand}

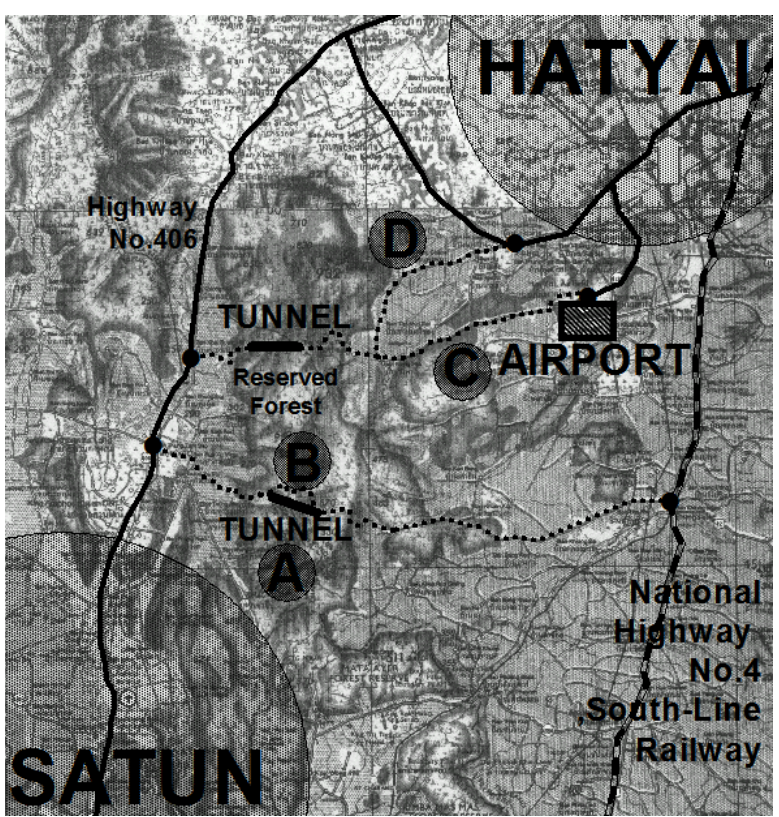

Figure 4. The Study Area
The goal of the project is to construct a two lane highway connecting Hatyai and Satoon province located in the southern part of Thailand. The proposed highway extends about $90 \mathrm{~km}$. length connecting the provinces in the South of Thailand. The main benefits of the project include savings of travel time and distance between southern provinces on the side of the Andaman Sea and the Gulf of Thailand. Other benefits include stimulating the trade in the southern part of the country, complement with the strategic policy regarding the national security in the southern part of the country, enhancing the potential for tourism development within the area. The project is responsible by the Department of Highway. The study area covers, mountains (in NorthSouth direction), national reserved forest, watershed areas, and agricultural land, see Fig.4.

There are four alternatives considered in this study. Table 3 provides some detail of the alternative highway corridors. The weights in the initial supermatrix were adapted from the feasibility study of the project (with agreed weights from experts). All cluster's inner dependences are set to 0.2. For demonstration, the initial supermatrix, weighted supermatrix, weighted supermatrix, and the limiting supermatrix for the benefit control criterion are illustrated in Table 4-6 respectively. The converged values of the elements in each row represent the global priority weights to the system. For example, from Table 6 the global priorities for each alternative with respect to benefit control hierarchy are $(0.086$, $0.088,0.083,0.080)$. The global weights may be normalized to get the relative weight of each alternative sum to one, e.g. $(0.257,0.261,0.247,0.236)$. For instance, with respect to benefit control hierarchy the corridor B is the best alternative with priority weight 0.261 . The priority of each indicator to the overall system could be obtained similarly by reading the stabilized column values. As stated earlier, the alternatives may be evaluated based on control hierarchies of benefits, opportunities, costs, and risks. The evaluation of alternatives with respect to other control hierarchies could be conducted in the same way as illustrated here. Finally, if each control hierarchy is weighted equally the overall evaluation of each alternative is synthesized by using Eq. (6), (Saaty, 1999).

$$
\text { Multiplicative Score }=\frac{(\text { Benefits }) \times(\text { Opportunities })}{(\text { Costs }) \times(\text { Risks })}
$$

Table 7 shows an example of synthesized scores using the above expression. The result obtained by ANP could be compared to the result of the feasibility study obtained from real experts.

\section{Conclusion}

This study proposed ANP as a novel approach to tackle the multicriteria highway corridor selection problem. The general structure of ANP and essential roles of stakeholders and experts were discussed in the paper. A simple numerical example was shown to illustrate the application of the model presented. It is generally believed that feeding more information to the model (or experts) would lead to better decision. The author suggests further study to interpret and investigate the effect of including more possible feedback blocks as added information to the proposed ANP model. 
Table 3. Detail of Alternative Highway Corridors

\begin{tabular}{|c|c|c|c|c|c|c|}
\hline \multirow{2}{*}{ Item } & \multirow{2}{*}{ Indicators } & \multirow{2}{*}{ Sub category } & \multicolumn{4}{|c|}{ Alternatives } \\
\hline & & & Corridor A & Corridor B & Corridor $\mathrm{C}$ & Corridor D \\
\hline $\begin{array}{l}\text { Land Compensation and } \\
\text { Relocation Costs }(\$) \\
\end{array}$ & Costs $(\$)$ & & 557,210 & 557,210 & $1,616,026$ & $2,696,314$ \\
\hline Construction Costs (\$) & Costs $(\$)$ & & $55,040,000$ & $303,085,000$ & $104,490,000$ & $102,747,500$ \\
\hline $\begin{array}{l}\text { Industiral and Tourism } \\
\text { Development }\end{array}$ & Qualitative & & Good & Good & Fair & Fair \\
\hline $\begin{array}{l}\text { Integrated Road Network } \\
\text { Strategy }\end{array}$ & Qualitative & & Good & Good & Fair & Fair \\
\hline Overall Length (km) & Length $(\mathrm{km})$ & & 95 & 97 & 83 & 82 \\
\hline \multirow{4}{*}{ Horizontal Curves } & \multirow{4}{*}{$\begin{array}{l}\text { Number of Curves } \\
\text { (Classified by Curve Radius, } \\
\text { m) }\end{array}$} & $\mathrm{R}<100$ & 0 & 0 & 0 & 1 \\
\hline & & $100<\mathrm{R}<300$ & 45 & 46 & 26 & 17 \\
\hline & & $300<\mathrm{R}<500$ & 3 & 6 & 3 & 6 \\
\hline & & $\mathrm{R}>500$ & 24 & 20 & 43 & 48 \\
\hline \multirow{4}{*}{ Vertical Curves } & \multirow{4}{*}{$\begin{array}{l}\text { Number of Grade Changes } \\
(\Delta \mathrm{G}, \%)\end{array}$} & $\Delta \mathrm{G}<4 \%$ & 37 & 33 & 46 & 46 \\
\hline & & $4 \%<\Delta \mathrm{G}<8 \%$ & 12 & 8 & 4 & 4 \\
\hline & & $8 \%<\Delta \mathrm{G}<12 \%$ & 6 & 13 & 5 & 5 \\
\hline & & $\Delta \mathrm{G}>12 \%$ & 0 & 1 & 0 & 0 \\
\hline \multirow{3}{*}{ Difficulties in Construction } & Tunneling (km) & & 2 & 0 & 6 & 6 \\
\hline & Bridges (total length, $\mathrm{m}$ ) & & 1,350 & 1,350 & 160 & 160 \\
\hline & Cut\&Fill (million cu.m) & & 3 & 4 & 2 & 2 \\
\hline \multirow{2}{*}{$\begin{array}{l}\text { Potential for Future } \\
\text { Improvement and Extension }\end{array}$} & Tunneling & & Yes & No & Yes & No \\
\hline & Right of Way (m) & & 40 & 40 & 30 & 30 \\
\hline $\begin{array}{l}\text { Expected Traffic Volume } \\
\text { (vehicle/day) }\end{array}$ & Traffic Volume (vehicle/day) & & 4,596 & 4,596 & 6,805 & 5,817 \\
\hline \multirow{4}{*}{ Road Network Efficiency } & Change in PCU-km & & $-124,181$ & $-124,181$ & $-121,339$ & $-105,352$ \\
\hline & Change in PCU-hr & & -148 & -148 & 382 & 533 \\
\hline & Change in Average Speed & & 0 & 0 & 0 & 0 \\
\hline & Change in $\mathrm{V} / \mathrm{C}$ & & 0 & 0 & 0 & 0 \\
\hline Soil Erosion & Qualitative & & Medium & High & Least & Medium \\
\hline \multirow{3}{*}{ Surface water } & \multirow{3}{*}{$\begin{array}{l}\text { Number of Crossings over } \\
\text { Natural Streams (Classified } \\
\text { by Width of Stream) }\end{array}$} & $\mathrm{W}>10 \mathrm{~m}$ & 1 & 1 & 0 & 0 \\
\hline & & $6>W>10 \mathrm{~m}$ & 5 & 5 & 3 & 5 \\
\hline & & $1<\mathrm{W}>6 \mathrm{~m}$ & 3 & 3 & 0 & 1 \\
\hline Underground Water & Length of Tunnel (m) & & 2 & 0 & 6 & 6 \\
\hline \multirow{5}{*}{ Air, Noise, Vibration } & Design Traffic & & 3,000 & 3,000 & 4,000 & 4,000 \\
\hline & $\%$ Truck & & 15 & 15 & 15 & 15 \\
\hline & Number of Temples & & 5 & 5 & 3 & 2 \\
\hline & Number of Villages & & 7 & 7 & 5 & 9 \\
\hline & Number of Schools & & 0 & 0 & 1 & 1 \\
\hline Watershed Ecosystem & Qualitative & & 2nd Class & 2nd Class & 1st Class & 1st Class \\
\hline Forrest & Qualitative & & \begin{tabular}{c|} 
Natural \\
Park+Tunnel
\end{tabular} & \begin{tabular}{|c|}
$\begin{array}{c}\text { Natural Park } \\
\text { Without } \\
\text { Tunnel }\end{array}$ \\
\end{tabular} & $\begin{array}{c}\text { National } \\
\text { Reserved } \\
\text { Forrest } \\
\end{array}$ & $\begin{array}{c}\text { National } \\
\text { Reserved } \\
\text { Forrest } \\
\end{array}$ \\
\hline Wildlife & Qualitative & & $\begin{array}{c}\text { Non-Wildlife } \\
\text { Sanctuary+Tu } \\
\text { nnel }\end{array}$ & $\begin{array}{c}\text { Non-Wildlife } \\
\text { Sanctuary } \\
\text { Without } \\
\text { Tunnel }\end{array}$ & $\begin{array}{l}\text { Wildlife } \\
\text { Sanctuary }\end{array}$ & $\begin{array}{l}\text { Wildlife } \\
\text { Sanctuary }\end{array}$ \\
\hline Residential Relocation & No. of Relocated Houses & & 42 & 42 & 117 & 308 \\
\hline
\end{tabular}


Table 4. The Initial Supermatrix for Benefit Control Criterion

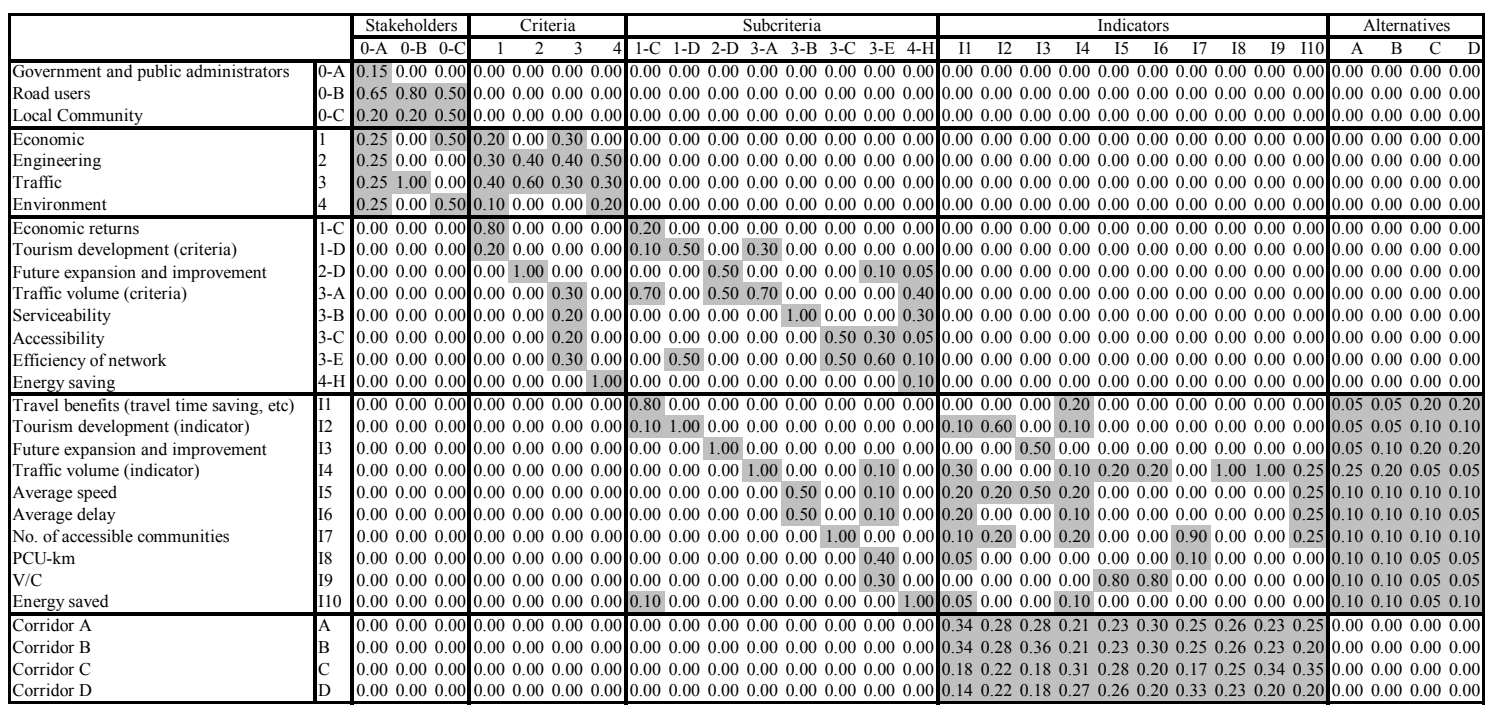

Table 5. The Weighted Supermatrix for Benefit Control Criterion

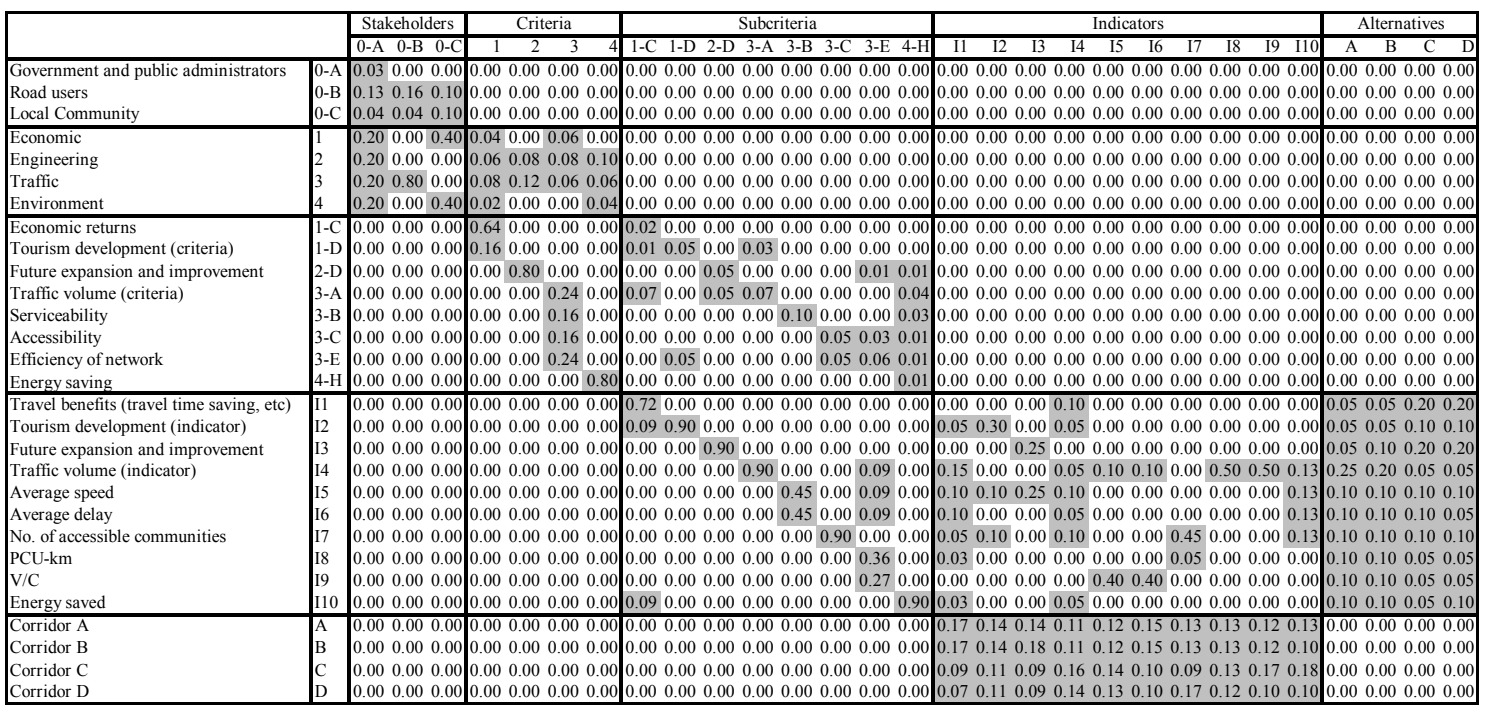

Table 6. The Limiting Supermatrix for Benefit Control Criterion

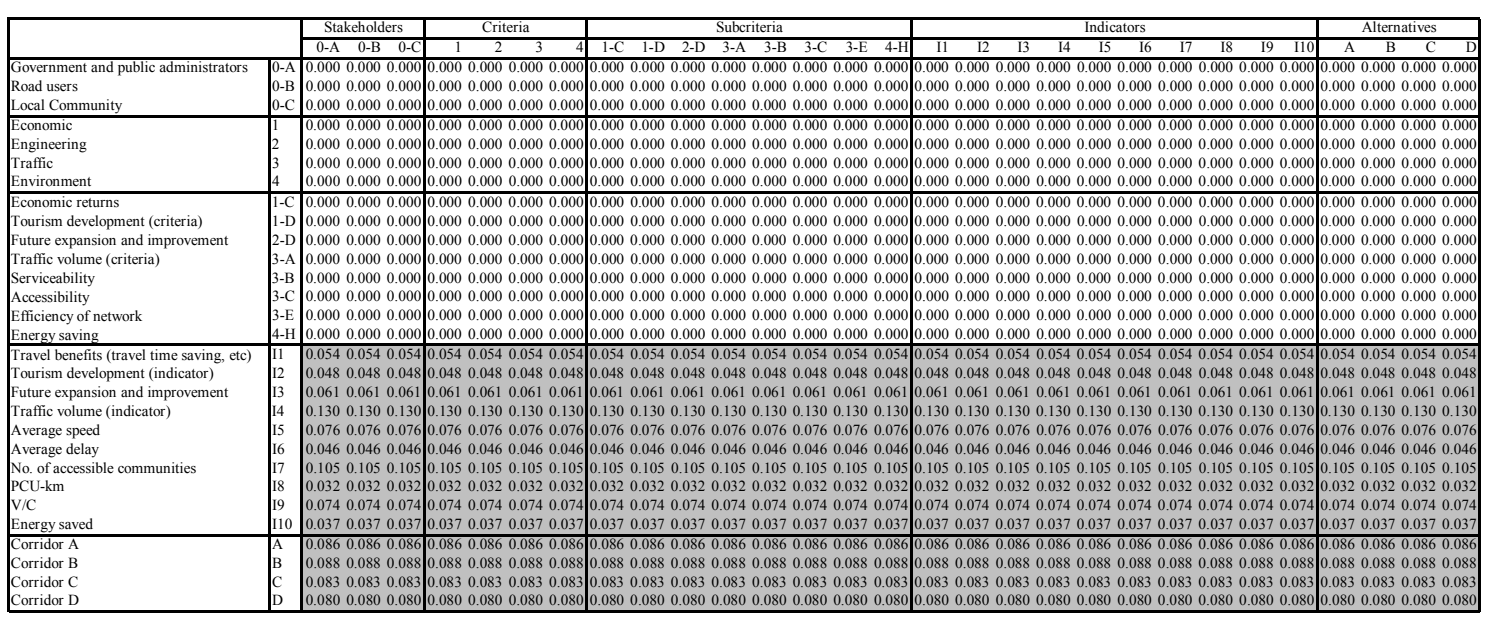


Table 7. The Calculation of Overall Evaluation Scores

\begin{tabular}{|l|c|c|c|c|c|c|}
\hline & B & O & C & R & Score & Normalized Score \\
\hline Corridor A & 0.257 & 0.264 & 0.265 & 0.212 & 1.205 & 0.291 \\
\hline Corridor B & 0.261 & 0.255 & 0.275 & 0.196 & 1.232 & 0.297 \\
\hline Corridor C & 0.247 & 0.245 & 0.244 & 0.284 & 0.872 & 0.210 \\
\hline Corridor D & 0.236 & 0.236 & 0.216 & 0.308 & 0.838 & 0.202 \\
\hline
\end{tabular}

(Note: Set by the author, for the numerical example purpose only)

\section{References}

Azis, I.J. (1990), “Analytic Hierarchy Process in the benefit-cost framework: A post-evaluation of the Trans-Sumatra highway project”, European Journal of Operational Research, 48, 38-48.

Bailey, K. (2003), “AMIS: Development and Application of a GIS/Multicriteria Corridor Evaluation Methodology”, Proceedings of the Map Asia 2003 Conference.

Bailey, K., Grossardt, T., and Jewell, W. (2005), "Participatory routing of electric power transmission lines using the EP-AMIS GIS/Multicriteria Evaluation Methodology", Proceedings of the 10th international symposium on information and communication technologies in urban and spatial planning and impacts of ICT on physical space (CORP 2005), 137-142.

Chowdhury, M. A., Tan, P., and Willam, S. L. (2002) An Interactive multiobjective decision support framework for transportation investment, Research Report, U.S. Department of Transportation Research and Special Programs Administration.

Forman, E., and Selly, M. A. (2001) Decision by Objectives, Expert Choice Inc.

Kalamaras, G.S., Brino, L., Carrieri, C. Pline, C., and Grasso, P. (2000), “Application of multicriteria analysis to select the best highway alignment”, Tunnelling and Space Technology, 15, 415-420.

Kale, M., S, Ravan, S., and Kaushal A. (2004), "GIS development of knowledge corridor along MumbaiPune expressway", Proceedings of the Map India 2004 Conference.

Piantanakulchai, M. (2005), "Computer based planning of intercity motorway alignment considering social and environmental impacts", Proceedings of the 15th International Road Federation (IRF) world meeting 2005, (Forthcoming).

Poonikom, K., O’Brien, C. , and Chansa-ngavej, C. (2004), “An application of the Analytic Network Process (ANP) for university selection decisions”, ScienceAsia, 30, 317-326.

Rogers, M., and Bruen, M. (2000), "Using ELECTRE III to choose route for Dublin port motorway", Journal of Transportation Engineering, July/August 2000, 313-323.

Saaty, T. L. (1980) The Analytic Hierarchy Process, McGraw-Hill, New York.

Saaty, T. L. (1999), "Fundamentals of the Analytic Network Process", Proceedings of ISAHP 1999, Kobe.

Shang, J.S., Tjader, Y, and Ding, Y. (2004), “A Unified framework for multicriteria evaluation of transportation projects”, IEEE Transactions on Engineering Management, 51, 300-313. 